\title{
Recession or resilience? Long-range socioeconomic consequences of the 17th century volcanic eruptions in the far north
}

\section{Heli Huhtamaa, Markus Stoffel, Christophe Corona}

5 Correspondence to: Heli Huhtamaa (heli.huhtamaa@ hist.unibe.ch)

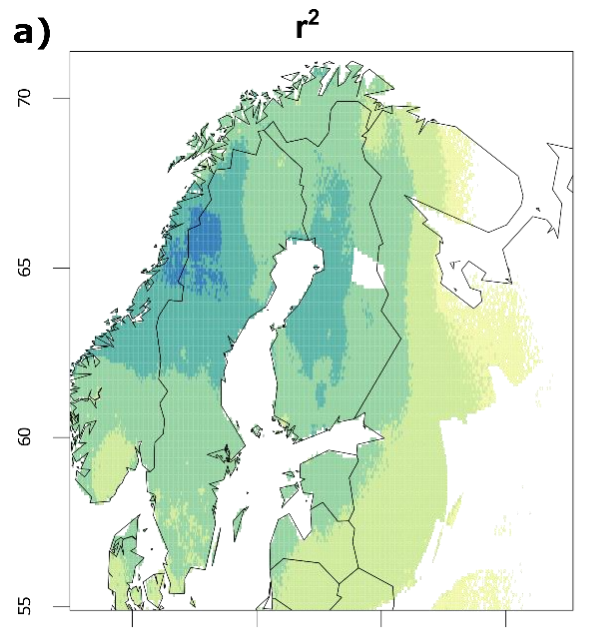

10

c)

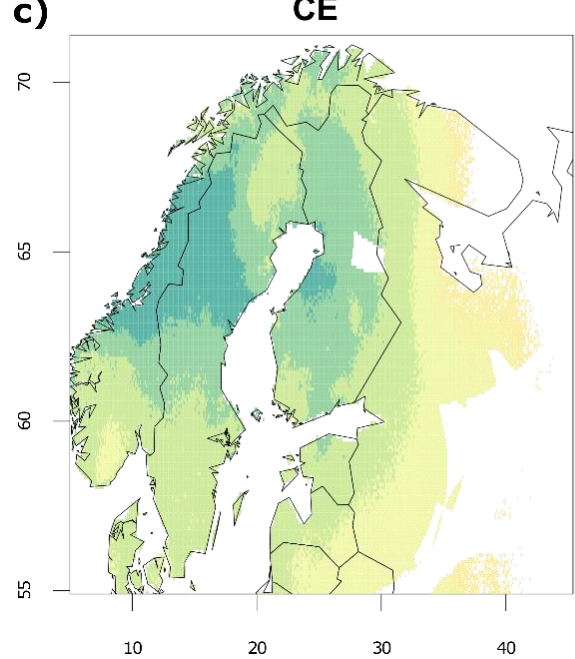

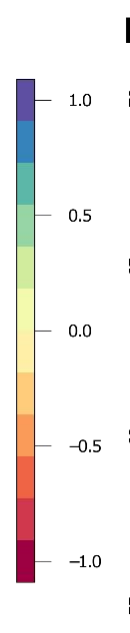

b)
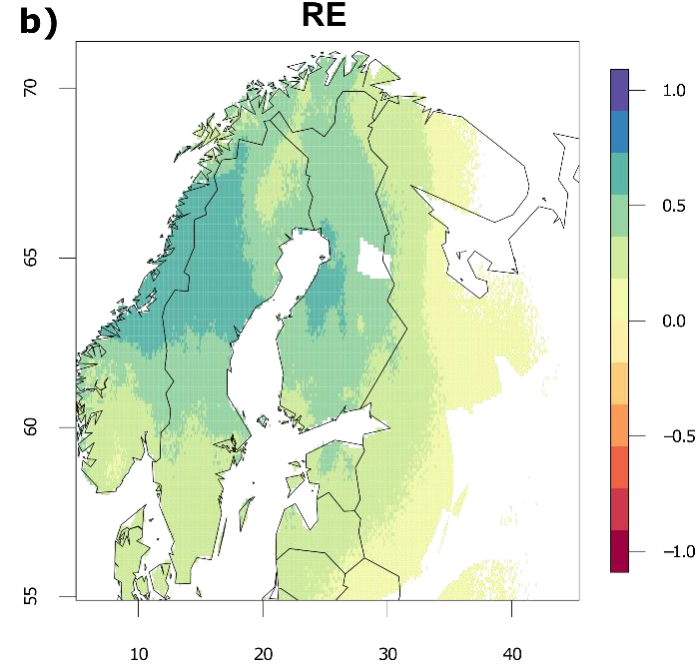
\section{)}




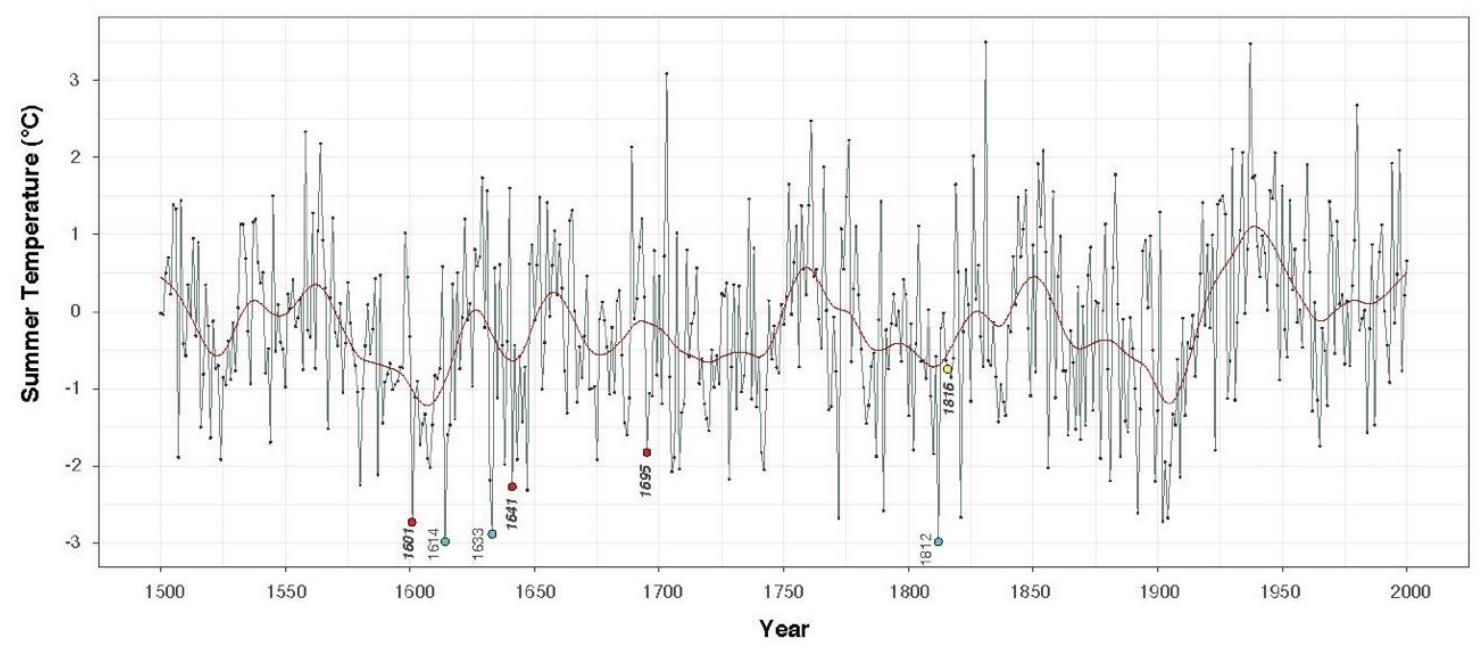

Figure S2. Summer (JJA) temperature anomalies (with respect to 1961-1990) reconstructed for the period 1500-2000 over Ostrobothnia. The red dots and years in bold indicates JJA the anomalies observed in the aftermath of the 1600 Huaynaputina, 1640/41 (Koma-ga-take and Mount Parker) and 1695 unidentified eruptions. Yellow dots show the cooling observed after the 151815 Tambora eruption. Blue dots show the three coolest summers $(1614,1633,1812)$ of the last 500 years. 